Revista Iberoamericana, Vol. LXXV, Núm. 227, Abril-Junio 2009, 349-362

\title{
UNA HERENCIA MONSTRUOSA: MESTIZAJE Y MODERNIZACIÓN EN CHILE
}

\author{
POR \\ SANDRA Garabano \\ Unversity of Texas at El Paso
}

Vicuña MackenNa y EL Mito DE LA Quintrala

Existe una figura legendaria en la historia colonial de Chile que ha capturado el imaginario nacional del país por su perversidad, crueldad y desenfreno sexual. Se trata de la Quintrala o doña Catalina de los Ríos y Lisperguer; una opulenta encomendera, mestiza, sádica y vengativa, con inclinaciones naturales a la violencia, a la brujería y al abuso de poder que en diversos momentos de su vida la arrastran a cometer asesinatos contra su padre, sus amantes y sus esclavos. Cuenta la leyenda popular que al regresar de una de sus frecuentes veladas sangrientas, la Quintrala se encuentra en su casa con una imagen del Cristo de la Agonía y, al sentirse juzgada por la mirada implacable del cristo, le ordena a un esclavo que se lo lleve de la sala. Mientras el esclavo obedece las órdenes y se dispone a llevar a la calle la imagen religiosa, la Quintrala se para en frente de la misma y le grita: "Yo no quiero en mi casa hombres que me pongan mala cara. ¡Afuera!”

Si la leyenda popular conecta la imagen monstruosa de la Quintrala con fuerzas mágicas y sobrenaturales, donde se mezclan el catolicismo y las religiones indígenas, Joaquín Edwards Bello, a principios del siglo xx, haciéndose eco de restos de discursos médicos y manuales de pedagogía, retoma la leyenda y explica de manera racional la conducta transgresora de esta mujer a sus lectores modernos:

Mi diagnóstico de la Quintrala, en sucesivas deducciones, es el siguiente: Irritación nerviosa por el mestizaje germano indio, educación restrictiva, sobreestimación, aislamiento y crueldad en el hogar, padres estrictos y de etiqueta, desconocimiento de las realidades materiales... hasta el punto de producir en ella un movimiento alocado de rebeldía, de inquietud y curiosidad por el hombre. (26-27)

En este traspaso del pecado al sistema nervioso, la concupiscencia de la carne adquiere nuevos significados y los fenómenos de brujería y posesión empiezan a explicarse como fenómenos patológicos asociados a las deformaciones del 
instinto y la degeneración racial. Desde su origen en el imaginario popular chileno hasta las representaciones teatrales más actuales, la vida de la Quintrala ha sido recogida en múltiples versiones. Esta legendaria figura fue leída en el siglo xIx por la historiografía liberal como la encarnación de los males del pasado colonial y la barbarie latinoamericana y reapropiada en el xx como símbolo de reivindicación del movimiento de mujeres. Desde las versiones orales narradas por el pueblo hasta las versiones cinematográficas y teatrales más recientes, sobre la monstruosidad de la Quintrala se pueden leer una serie de ficciones en torno a diversas subjetividades que conformarán el origen de la nación chilena. Si la fundación de la nacionalidad requiere de la negociación de conceptos de raza, género y etnicidad, en Chile, el cuerpo enfermo de esta mujer ofrece un espacio de negociación a partir del cual explicar las contradicciones del proceso de fundación de la nacionalidad dentro de los límites de la modernización liberal. En otras palabras, el cuerpo mestizo de la Quintrala se vuelve una herramienta retórica para explicar las contradicciones del proyecto del estado liberal a la hora de integrar el pasado, colonial e indígena, al futuro de la nación. De esta manera, del lenguaje mágico y sobrenatural de la leyenda pasamos al lenguaje racializado y a las especulaciones biológicas que transformarán la herencia de la nación y posibilitará el surgimiento de un Chile regenerado donde la historia del país vuelve a coincidir con la historia de sus familias más prominentes.

Al lograr resolver los conflictos internos y consolidar el estado con anterioridad al resto de América Latina, Chile se imagina a sí mismo, desde muy temprano, como la "raza privilegiada de América” (Collier y Sater 103). En este trabajo me gustaría explorar las contradicciones sobre las que se funda esta temprana consolidación del estado moderno y analizar las relaciones entre el surgimiento del estado nación y la aparición de una literatura sobre la regeneración de la población como mecanismo de creación de una ciudadanía chilena. Me gustaría proponer que al resolver los conflictos territoriales y políticos entre liberales y conservadores antes que en el resto del continente, Chile ubica al patrimonio biológico de la nación en el centro de las discusiones políticas sobre las que se funda la nacionalidad.

En uno de los países considerados más blancos de Hispanoamérica, las elites liberales chilenas, discuten de manera casi obsesiva, hasta ya entrado el siglo xx, las influencias ambientales y el legado racial de la nación. En el diagnóstico de los males heredados de la colonia, modernizar la nación será en Chile, más que erradicar a los pobladores originarios de América como plantea Sarmiento en el Facundo, regenerar su sangre y corregir la herencia monstruosa asociada a la mezcla racial. Una de esas primeras ficciones en torno a la regeneración de la nacionalidad tiene que ver precisamente con el mito de la Quintrala. La figura monstruosa de esta mujer legendaria cautiva al historiador Benjamín Vicuña Mackenna quien en 
1877 publica Los Lisperguer y la Quintrala. Doña Catalina de los Ríos. El texto de Vicuña constituye la primera versión escrita de la leyenda popular y el historiador así lo reconoce en su texto:

No queremos hacer cuenta abultada del trabajo que esta empresa ha podido costarnos. Bastará decir que ni uno solo de los cronistas e historiadores, tanto antiguos como modernos, ha mencionado siquiera el nombre de esta mujer, que desde hoy pasará a ocupar un sitio preferente entre los más notorios y abominables delincuentes de cualquier país del mundo. (10)

En el texto de Vicuña, el personaje la Quintrala está construido casi en el límite entre un estudio de caso y la representación del "salvaje" de la literatura romántica latinoamericana: "Doña Catalina de los Ríos, como las fieras dañinas y bravas, mordía a sus presas los miembros de su cuerpo antes de matarlas. Era una chacal hembra pero no era una mujer" (114). ${ }^{1}$ Con la publicación de la leyenda, esta mujer, con "impía crueldad de monstruo" (110) se volverá crucial a la hora de pensar el origen de la nacionalidad chilena. A partir de ella, Vicuña se propone reconstruir la historia social del pueblo chileno y, sobre todo, recrear el linaje de la nación, a través del trazado de una nueva genealogía donde la sangre criminal de los Lisperguer va a regenerarse en su escritura. El mismo Vicuña en su libro sostiene que "como ha anunciado uno de los genealogistas en Santiago el que no es Lisperguer es mulato" (10) y entre ambas opciones, Vicuña prefiere ubicar el origen de la nación en el mestizaje europeo e indígena de los Lisperguer, que a pesar de sus tendencias criminales y pecaminosas será siempre más propenso al blanqueamiento que la raza negra.

En el traspaso de la cultura popular a la cultura letrada en el siglo xix, el mito pierde su riqueza narrativa y adquiere un tono de pericia médico-legal, donde se mezclan la moral y los nuevos avances de la medicina presentes en la nueva sensibilidad decimonónica. Al mismo tiempo, en ese traspaso, pasamos de la monstruosidad provocada por un desorden a la ley natural a una monstruosidad originada en la conducta donde el monstruo pone en entredicho cierta prohibición de la ley civil o religiosa. En ese sentido, la Quintrala, como mujer que se entrega a una sexualidad desenfrenada e improductiva y en su carácter de propietaria de una encomienda, ofrece un campo de anomalía para el futuro de la nación, propicio para la intervención de una persona calificada y avalada por el discurso de verdad que ofrece la historia:

\footnotetext{
1 Esta descripción de la Quintrala, donde los límites entre la vida humana y la vida animal se desdibujan, es común en las descripciones de los indios/as en obras claves del siglo xIx como La cautiva de Esteban Echeverría o el Martín Fierro de José Hernández.
} 
Por otra parte, el presente estudiono será solo un episodio aislado, un rasgo biográfico de la era colonial: es un cuadro más o menos imperfecto y mal bosquejado, pero fiel y curioso, de esa misma era. No es doña Catalina de los Ríos un tipo en la vida tenebrosa de nuestros mayores, pero en los accidentes que rodearon su cuna, en su educación, en su vida de encomendera y cortesana, tiene de seguro algo que aprender el historiador y no poco que meditar con provecho y enseñanza el filósofo social. (11)

Vicuña Mackenna escucha el mito popular y lo interviene a través de la historiografía; en esa intervención, la memoria colectiva es reemplazada por la voz del experto que inaugura un nuevo lugar de enunciación donde fronteras entre el historiador y el médico son todavía borrosas. De esta manera, al entrar a la escritura, el mito adquiere el carácter de un discurso científico que servirá como una especie de estructura de recepción y ordenamiento del monstruo creado por la imaginación popular, y así la magia y la brujería que habían cautivado la imaginación del pueblo pasan a explicarse como un accidente generado por el encuentro sexual entre un alemán y una india americana. Además de este accidente, su condición de mujer que reclama una sexualidad que no es necesariamente canalizada en el seno de la familia, y es dueña de las tierras más ricas de Santiago y sus alrededores, constituye todo un campo de transgresiones que requieren la intervención del saber de un experto. Más adelante el historiador escribirá:

Nosotros, sin embargo, no vamos a estudiar ni contar la vida de aquella aristocrática raza, mitad alemana, mitad india, a la luz de los blasones, sino de la filosofía social ehistórica que sus cruzamientos domésticos y su influencia política marcan, porque la leyenda de esa familia es la vida verdadera de la colonia y de su siglo. (12)

Al diferenciarse de la historiografía colonial, en la que importa solo la heráldica, y al transformar la voz del pueblo, el discurso historiográfico adquiere, en el texto de Vicuña, el poder de normalizar el mito. Sin embargo, en el proceso de normalización, el historiador no intentará borrar el saber del otro, la función de la norma no será excluir el saber popular, tampoco rechazarlo, sino corregirlo. En La Quintrala, de Vicuña Mackenna, los monstruos del pasado, aquellas arpías medievales, mezcla de pájaros y mujeres, que implicaban una transgresión a la ley natural, darán lugar a los nuevos monstruos del presente, “esos monstruos trivializados y empalidecidos" que Foucault asocia a los seres incorregibles que se resisten a las técnicas de domesticación modernas (Los anormales 295). La monstruosidad de la Quintrala, como la de esos monstruos modernos que describe Foucault, está unida al surgimiento de un discurso de expertos en torno a la perversidad en el que predominan términos como orgullo, empecinamiento, lascivia y pereza. La 
monstruosidad, entonces, más que la deformidad física o una transgresión a la ley natural, será ese límite borroso entre la enfermedad y la deficiencia moral (Los anormales 299). Se trata de monstruos cotidianos que, como en el caso de la Quintrala, se niegan a ofrecer sus cuerpos a las tecnologías de intervención moderna que intentan convertirlos, guiarlos y transformarlos en los cuerpos productivos que necesita el futuro de Chile.

En el proyecto historiográfico liberal iniciado por Vicuña Mackenna, el trastorno narrativo, sexual y racial de la Quintrala se convertirá en un campo de intervención privilegiado en el proceso de construcción y regeneración de la nación moderna, ese espacio inmune a cualquier tipo de heterogeneidad que imaginaron los intelectuales latinoamericanos del siglo xIx. El cuerpo y la moral incorregible de la Quintrala, atravesados por el discurso religioso de la confesión y las poseídas de la época colonial, nos remiten a la memoria popular donde los límites entre el pasado y el presente, y la cultura europea y la cultura indígena, apenas se distinguen. Ese trastorno temporal y cultural se convertirá para Vicuña Mackenna en un obstáculo a la hora de construir el futuro de la nación y será el historiador quien a través de la higienización del mito nos ayudará a restablecer el orden temporal que requieren las nuevas retóricas del progreso. De esta manera, a través de la normalización del mito, la nación quedará purificada de su propio pasado. El mito popular le ofrece al historiador un origen ominoso para la nación, pero al mismo tiempo se constituye en un principio de inteligibilidad para corregir el pasado y entender el presente. La herencia monstruosa del pasado indígena y colonial reflejada en el mito popular de la Quintrala le va a ofrecer al historiador un campo de anomalías alrededor del cual éste desarrollará una serie de tecnologías de intervención políticas necesarias para la creación de la nación moderna; entre esas tecnologías, la traducción del mito a la historiografía liberal será crucial.

La mujer perversa y criminal, la mestiza enferma e indomable se explica en el texto de Vicuña Mackenna a partir del surgimiento de la pericia médico-legal que Foucault ubica a principios del siglo xix. Para Foucault, cuando lo patológico entra en escena, la criminalidad desaparece ya que la ley no puede castigar al loco. Sin embargo, con la creación de la pericia médico-legal, las fronteras entre terapéutica y castigo, enfermedad y responsabilidad, medicina y penalidad, hospital y prisión, comienzan a borrarse:

En términos generales se puede decir lo siguiente: la pericia contemporánea sustituyó la exclusión recíproca del discurso médico y el discurso judicial por un juego que podríamos llamar de la doble clasificación, médica y judicial. Esta práctica, esta técnica de la doble calificación, organiza lo que podría llamarse el dominio de la perversidad. (Los anormales 40) 
Para Foucault, alrededor de este dominio va a surgir la voz del experto enunciando ciertos elementos biográficos como la maldad, la pereza, el orgullo o la lascivia que van a prefigurar, generalmente en la infancia, la escena del crimen (41). Vicuña asume la voz del experto a lo largo del texto para explicar el origen de los crímenes de las Lisperguer y presenta a la infancia como esa temporalidad propensa a la "enfermedad": "Y esa familia, mezcla de tantas razas, traía la pubertad anticipada desde su primera precoz y voluptuosa niñez, especialmente, en las mujeres” (Quintrala 154). La voz del experto aparece también para diferenciar su propia historia de la leyenda popular:

Los casos de impúdica y feroz liviandad de que la tradición inculpa a doña Catalina de los Ríos son varios, y todos, más o menos horribles. Pero nosotros no haremos caudal de ellos, porque escribimos una historia social, estrictamente verdadera y conforme a documentos fehacientes, dejando a otros lo pintoresco y abultado. (71)

Sin embargo, el gran monstruo que se esconde detrás de las diversas anomalías de la Quintrala, la figura esencial alrededor de la cual se organizan otras instancias del saber, como la pedagogía o la sexualidad, es el discurso de la degeneración racial que logrará detectar el monstruo del mestizaje:

Y a fin de explicarse a sí propio, a través de los años y con más acierto, el observador moderno esos horrores, conviene notar desde luego que, aparte de la educación viciosa, de los malos ejemplos del hogar y de las propensiones generatrices de su ser y de su sexo, tuvo doña Catalina de los Ríos una extraña y terrible mixtión de sangre, porque si por su padre y su abuela, la Encío era de estirpe genuina de España, por su madre dona Catalina Lisperguer y Flores (Blumen) era dos veces alemana y una vez india chilena... ¿ ¿Había en esta mezcla de raza fundidas rápidamente en un solo tipo algo que predisponía al crimen y al mal? (Quintrala 65)

Es por eso que al diagnosticar los males hereditarios el texto de Vicuña se convierte en una lección edificante para el futuro de la joven nación. Establecer esta especie de biografía de la nación a través de la narración de la historia de la familia Lisperguer va a permitir desarrollar una serie de procedimientospara analizar, reconocer y en última instancia regenerar las almas y los cuerpos transgresores del pasado y transformarlos en los cuerpos útiles, dóciles y productivos de los futuros ciudadanos chilenos. 
HISTORIA CHILENA Y MESTIZAJE:

CONSENSO, SABER HISTÓRICO Y SABER POPULAR

Para Vicuña, la regeneración de la nación -que, en cierto sentido, se opone al discurso de exterminio, desarrollado por ejemplo por Sarmiento y Alberdi en Argentina- es posible porque Chile puede crear una nación viable mucho más temprano que el resto de las repúblicas latinoamericanas. En Chile, contrariamente a lo que ocurre en otros países latinoamericanos, se desarrolla una política de consenso entre conservadores y liberales quienes, a pesar de sus fricciones, llegan a acuerdos políticos que harán cada vez más borrosas sus propias diferencias. De modo que el proceso de reconciliación de los liberales con el pasado autoritario del gobierno conservador de Diego Portales será construido cuidadosamente a través de la historiografía. El papel preponderante dado a la historia en esta época de reconciliación nacional ha llevado a algunos historiadores a relacionar el surgimiento del sentimiento de la nacionalidad con el entusiasmo por la narración de la historia nacional. Para Rénique, Vicuña Mackenna reivindicará, por un lado, a los caudillos liberales que habían quedado afuera de la historia oficial a través de la escritura de la biografía de los héroes de la independencia exiliados de dicha historia oficial (13). Vicuña busca conciliar en la escritura de la biografía de los hermanos Carreras y de O'Higgins los dos proyectos de nación que se disputaban la dirección del estado chileno. En ese sentido, el proyecto historiográfico de Vicuña tendría como objetivo integrar a los caudillos liberales a la historia de la nación, buscar una imagen de reconciliación de la historia que había sido quebrada en los decenios de 1820 y 1830 y que lo habían mandado al exilio por complotar contra Portales (14). Después de la guerra de Independencia contra España y frente a una América Latina dividida y gobernada por diferentes caudillos, Chile aparece en la historia política latinoamericana como una excepción. En palabras de Tulio Halperin Donghi, en el siglo xix, Chile gana un prestigio sin precedentes frente al resto de las repúblicas latinoamericanas, y es precisamente en esta época donde aparece la noción, admirada por varios de sus vecinos, de un país en el que, a pesar de los conflictos, la política será siempre ordenada y estará en manos de hombres civilizados.

La idea de Chile como el único país latinoamericano en el que no se ha interrumpido el proceso de modernización es atribuida, por lo general, a la existencia de una estructura social en la que coexisten un pequeño grupo de criollos de clase alta sin grandes divisiones económicas junto a una mayoría de campesinos generalmente mestizos y pobres que no entrarán a la vida política del país sino hasta el siglo xx. A esta estructura de clase habría que agregarle la falta de diversidad regional según la cual, contrariamente a lo que ocurriría en México o Argentina donde el interior ofrece una fuerza alternativa al poder de la capital, las provincias del norte y del sur 
de Chile no tendrían el poder económico necesario para contrarrestar la hegemonía de Santiago. Sin embargo, la relativa estabilidad política del país no responde solo a una situación geográfica y social supuestamente favorable, por el contrario fue construida cuidadosamente por los partidos conservadores a partir de la década del treinta bajo de dirección política de Diego Portales. Frente a las convulsiones internas que se dan en México y en Argentina que culminarán con la llegada al poder de Santa Anna y Rosas, Portales, a pesar de su autoritarismo, es percibido como la causa que inhibe esa tradición violenta de caudillos fuertes que amenazará al resto del continente. De modo que, bajo un gobierno fuerte y centralizado, Chile consolida el estado, delimita sus fronteras nacionales y somete la diversidad cultural del país con anterioridad al resto de los países latinoamericanos.

Este proceso de consolidación del estado nacional fue percibido en el exterior como un camino sin interrupciones hacia el progreso. Mientras en Argentina el gobierno de Rosas obstaculizaba el sueño modernizador de Sarmiento y en México la guerra contra los Estados Unidos desestabilizaba las fronteras nacionales, Chile, paraíso del progreso para intelectuales como Bello y Sarmiento, parecía dirigirse de manera casi providencial a cumplir el sueño de la civilización.

La batalla contra el pasado español, la pacificación de la Araucanía y el traslado de la civilización que florecía en Santiago al interior del país, parecían obstáculos insignificantes al lado de la virulencia de las luchas internas bajo el gobierno de Rosas en Argentina o la extravagancia casi grotesca con la que Santa Anna dirige la vida política de México. En el marco de esta estabilidad política creada por el gobierno de Diego Portales, se produce un importante desarrollo cultural que va a originar la noción de Chile como la república modelo de Sudamérica; el país parecía estar a salvo de la violencia dictatorial, la barbarie de los gauchos, e incluso su propia población indígena había sido integrada al proyecto nacional a través de $L a$ araucana, un poema épico que no dejaba ninguna duda de que el indígena podía integrarse, al menos simbólicamente, a la gran tradición de la cultura occidental. De modo que Chile se encontraba a salvo de los males que los intelectuales liberales diagnosticaban en el resto de América Latina.

Benjamín Vicuña Mackenna entendía que uno de los secretos de la estabilidad política e institucional en Chile era la intervención electoral, que el poder ejecutivo manipulaba las elecciones y que el congreso era generalmente elegido por el presidente. Es así que en la república modelo de Sudamérica, donde el producto de las haciendas y las minas llegaba al resto del mundo a través de las reformas que fomentaban el libre comercio, todo levantamiento que intentara modificar este punto en la constitución fue derrotado.

La civilización, el progreso, el libre comercio, el telégrafo y el ferrocarril serán los términos evocados por los conservadores cada vez que tienen que reprimir las 
revueltas de los jóvenes liberales, quienes ven con pesimismo cómo la república democrática era desplazada en la década del treinta por el régimen autoritario de Diego Portales.

En 1853, Benjamín Vicuña Mackenna deja Chile tras participar en un levantamiento político en contra del gobierno conservador de Manuel Montt. Después de un recorrido que se inicia en San Francisco e incluye México y el sur de los Estados Unidos, llega a Boston y queda sorprendido frente a la hospitalidad de sus habitantes. Cansado de sufrir "el calor y la ociosidad de la tierra caliente" (Páginas de mi diario 101) se alivia al llegar a Nueva Inglaterra y reconoce sentirse "quite at home" (153) en el seno de una familia puritana. En su diario de viaje, mientras recuerda su visita en casa de la familia de uno de sus compañeros de viaje norteamericanos, parece olvidarse de los conflictos políticos que lo habían obligado a dejar su país y escribe: "Yo me complazco, tal vez, en recordar estos incidentes, no por su originalidad, sino en cuanto ligan mi memoria y mi gratitud a los únicos días en el extranjero en que he podido tener la ilusión de que no había dejado del todo mi patria...” (158). En la memoria del viajero llegar a Boston es llegar a Chile; de esta manera Vicuña Mackenna traza un mapa que no sólo le permite redefinir la identidad de su país sino delimitar el lugar que ocupará Chile en relación al resto del continente: en su imaginación no hay nada en México ni en la América española que le recuerde a su patria. Para Vicuña, Chile parece haber alcanzado ya la modernización política y cultural que se había interrumpido en el resto de América Latina. Si Sarmiento en Conflictos y armonías de las razas en América todavía insiste en que Argentina debe parecerse a los Estados Unidos, en 1852 Vicuña reconocía satisfecho en el seno de una familia yankee que Chile ya había alcanzado la utopía de la modernización.

Unas páginas más adelante y después de haber sufrido las inclemencias del clima de Nueva Inglaterra, Vicuña recuerda en su diario las palabras del historiador W. H. Prescott: "Qué habría sido de la América del Sud con su maravillosa naturaleza, poblada por las razas del norte” (167). Esta visión de la América española, lanzada como expresión de deseo de un historiador norteamericano, se convertirá en el programa político de los intelectuales liberales del siglo xix latinoamericano. Cómo convertir las formas de vida primitivas asociadas a los pobladores de América Latina en la raza disciplinada y moderna de América del Norte, cómo corregir y someter la diversidad de la barbarie hispanoamericana a la ley racional de la civilización que el viajero descubre en su viaje por América del Norte. Después de atravesar las tierras turbulentas de Santa Anna, Vicuña presiente que Chile tiene ciertas ventajas frente al resto de América Latina y presentará a su país como una república modelo. Al carecer de una tradición de caudillos violentos y de las intensas divisiones regionales que amenazaron el proceso de modernización en el 
resto de América Latina, en Chile, la guerra sobre la barbarie se vuelve una guerra en torno al patrimonio moral y biológico de la nación.

$\mathrm{Si}$, como plantea Julio Ramos, los estados nacionales se consolidaron a partir del sometimiento de la heterogeneidad latinoamericana a la homogeneidad que requería de cuerpos dóciles y ciudadanos subordinados a las leyes que exigía un incipiente mercado, en el caso chileno la barbarie latinoamericana se verá atravesada por el discurso de la regeneración. Dentro de ese discurso, el mestizaje será presentado como una anomalía en el cuerpo social de la nación. En otras palabras el mestizo será el anormal y se convertirá casi automáticamente en una herramienta de análisis al diagnosticar los males de la nación. Detectar esa especie de monstruosidad que se encuentra en el origen de la nacionalidad será fundamental para desarrollar un dispositivo de gobierno de las almas y los cuerpos en el proceso de creación de una ciudadanía moderna.

En una visita a Buenos Aires durante el gobierno de Rosas, inspirado por el recuerdo de la gesta independentista, Vicuña escribe:

Después de la independencia, Chile ha tenido dos revoluciones: la de 1829 y la de 1851. Aquella la hizo el Pasado. La última fue la expresión del presente agitado y laborioso. Falta hoy día la Revolución del Porvenir!

Y ella aparece augusta en el horizonte sin sangre de batalla, sin sogas de horcas, ni cadenas de prisioneros, ni listas de proscriptos, porque ella es la obra de la inteligencia laboriosa y fecunda, de la fe y del amor, del alma y de la conciencia, de las ideas que han de operar en un día no remoto la regeneración del linaje humano... (386)

Si el pasado está marcado por la guerra entre españoles y criollos y el presente por los conflictos entre liberales y conservadores, la guerra futura no será una guerra que tiene como sustrato relaciones sociales o políticas, no habrá batallas, ni exilio, ni siquiera sangre; será una guerra de ideas, una guerra que logre intervenir y normalizar el origen de la nación, una guerra alrededor de la cual se organizarán distintas instancias de saber en torno a la renovación de la vida. En cierto sentido Vicuña prefigura o se anticipa a las ideas de Spencer que sostienen que las sociedades se desarrollan y se organizan de acuerdo a las mismas reglas que los organismos vivos. Esta revolución del porvenir como la llama Vicuña no será una batalla en el sentido guerrero sino que estará asociada a la renovación de la vida, la regeneración de la nación ya no estará ligada a la lucha entre distintos sectores que se disputan determinados privilegios, sino a la transformación de los hombres. La lucha por la civilización ha dejado de ser un conflicto político y social para convertirse en un dispositivo de intervención para lograr el mejoramiento de lo humano, en otras palabras, se trata de intervenir sobre la vida para crear futuros 
chilenos agentes del progreso. Lo biológico, tradicionalmente excluido de la política, se vuelve parte integral de la misma y nos remite al discurso médico asociado con la enfermedad que prefigura la aparición del crimen que amenaza el futuro de la nación: la reproducción entre un alemán y una india americana, que ha provocado la degeneración de la raza chilena. Vicuña vuelve a este momento en la vida de la nación reiteradamente en su texto sobre la Quintrala: "En cuanto a la manera como vino a ajustarse aquel fatal consorcio de dos familias, en que las afinidades del crimen producirían un ser deforme en la maldad, diremos desde luego lo que como verdad ha llegado hasta nosotros" (57).

Al regreso del exilio, Vicuña entenderá la historia como un vehículo para llevar adelante su proyecto de regeneración de la patria, la historiografía junto a las reformas arquitectónicas que realiza como intendente de la ciudad de Santiago serán dispositivos fundamentales para ordenar el desorden político de los años de lucha entre liberales y conservadores, pero la historia será también el lugar elegido para narrar la regeneración de la herencia biológica, un dispositivo para corregir la herencia monstruosa del mestizaje chileno, y aquí la reescritura del mito de la Quintrala ocupará un lugar fundamental. Será precisamente Vicuña Mackenna, a través de su proyecto de transformación de la ciudad de Santiago, basado en modelos científicos franceses, una figura central en la formación de un discurso de intervención social en relación a la salud de la población. Como parte de la nueva utopía urbana que imagina Vicuña, se llevan a cabo una serie de obras públicas y se construye el muro sanitario para proteger la salud de la población. Entre las reformas arquitectónicas que impulsa como intendente de Santiago los criterios estéticos y disciplinarios parecen no tener límites demasiado claros y la sanidad y la higiene de la ciudad van a reemplazar el discurso religioso de la moral. Como muestra Leyton Robinson en su artículo sobre la transformación de Santiago, hay siempre en los planes de Vicuña un significado social de la belleza citadina, en ese sentido, la renovación del cerro Santa Lucía tendrá como objetivo crear formas higiénicas de recreación social. Además de en la arquitectura, será en la narración de la historia donde Vicuña encontrará la forma de establecer el consenso político que necesita la nación para poder entregarse a la tarea modernizadora que había sido interrumpida en el resto de América Latina. En ese sentido la publicación de La Quintrala es clave, ya que en este texto Vicuña expresa de manera explícita su intención de limpiar a la nación de su propio pasado a través de la escritura:

Yasí como sin pasión ni propósito de secta iremos vengando el pasado, depurándolo, así correrá la pluma feliz y casi ufana al trazar las páginas honrosas de esa extraña raza, generatriz de la nuestra, que produjo a la vez héroes y monstruos, ángeles y arpías. (10) 
A través de la pluma feliz de la historia Vicuña se propone trazar la biografía de la nación para romper con la fatalidad del mito y, de esta manera, entregarse a construir la utopía del futuro. Si antes había escrito la biografía de los héroes, ahora es necesario redactar la biografía del monstruo. Como Sarmiento en el Facundo, Vicuña traza la biografía de la barbarie, pero a diferencia de Sarmiento, que al final del Facundo resuelve los conflictos entre la civilización y la barbarie por la intervención casi mágica del progreso, Vicuña no deja que el azar resuelva el destino de Chile, al contrario, en la regeneración del país interviene una voz calificada. A través de la narración de la historia de varias generaciones de familias aristocráticas de origen vasco, el historiador logra corregir y purificar aquel origen ominoso de la patria en la sangre mestiza de la Quintrala. La escritura de la historia y la profusión de sangre vasca se vuelven una especie de saber de reparación del pasado. En esta regeneración de la sangre, Vicuña irá mostrando cómo la sangre criminal de los Lisperguer se irá purificando a través de la mezcla con sangre de familias ilustres:

Pero, descendiendo de las regiones del misticismo y sus patrañas a que nos ha conducido un momento el solo propósito de dar a conocer por entero una época no estudiada todavía, cúmplenos ahora referir cómo los Lisperguer de Purutún, convertidos ya en Amaza, se tranformaron después en Azúa, enseguida en Marín de Póveda por último en Cortés, todo en el espacio de un siglo... (18)

El texto de Vicuña crea una voz que es a la vez la del historiador y la del médico que se constituye en una figura central a la hora de legitimar los campos de saber y de poder sobre los que se funda la nación. En otras palabras, la historia como procedimiento retórico logra devolverle a Chile un pasado limpio, donde la sangre indígena se minimiza o desaparece por la transfusión de sangre de la aristocracia española, un pasado sin violencia ni transgresiones que será instrumental a la hora de imaginarse a sí mismo como república modelo de la utopía modernizadora latinoamericana.

En la escritura de La Quintrala, Vicuña cumple el sueño que había imaginado en el seno de una familia protestante durante su viaje por los Estados Unidos: el de un Chile modelo, regenerado a partir del aporte de sangre de la aristocracia española. Vicuña es selectivo en cuanto a la inmigración y jamás imagina un desierto poblado de trabajadores protestantes como en la utopía de Sarmiento; el corte con el pasado no es definitivo como en Argentina: Vicuña rescata en la colonia el aporte de la inmigración vasca y en ella deposita su sueño de regeneración. Es por eso que, en el proceso de reescritura del mito, Vicuña pone en el centro de la discusión la herencia biológica de la Quintrala: el texto narra desde los orígenes de la familia, su degeneración por la mezcla de sangre alemana e indígena y su regeneración a partir 
de la sangre de la familia Irarrázabal. Si la familia de la Quintrala, y su constante abuso del poder, es asociada al pasado colonial y a la fluidez con que en ese pasado se mezclaban la sangre, la cultura y la religión, el futuro será imaginado como el restablecimiento de la justicia republicana, pero también como ese lugar donde se restablecen fronteras restringidas entre las clases y las razas. La relación entre el pasado y el futuro es compleja en Vicuña, ya que, si bien La Quintrala admite una lectura alegórica del abuso de poder en la época colonial, es precisamente en ese pasado colonial donde encontraremos también la semilla de la regeneración:

Pero el enlace que dio mayor realce, esplendor y nueva vida al astro de los Lisperguer... fue el de la más discreta, más pura y casta entre las castas hijas del castizo Juan Rodolfo Lisperguer y doña Catalina Lorenza de Andía Irarrázabal. (186)

Contrariamente a lo que ocurre con la sangre de doña Catalina Lorenza de Andía Irarrázabal que logra purificarse y borrar las contaminaciones raciales, esto es, la sangre de los Lisperguer, la sangre convulsionada de doña Catalina de los Ríos Lisperguer no admite el proceso de purificación. La lascivia y obstinación de la Quintrala no se regeneran ni con el matrimonio ni con la educación, ni con su exilio de Santiago y el contacto con el aire puro de los campos de La Ligua. Si, como plantea Foucault, la convulsión es un paso adelante en la historia política del cuerpo que surge como reacción al confesionario y a las tecnologías modernas que intervienen el cuerpo deseante, el cuerpo convulsionado y monstruoso de la Quintrala, retenido por la memoria popular, tendrá que desaparecer para que la nación se regenere en ese otro cuerpo dócil de doña Lorenza Irarrázabal quien para Vicuña "fue la mejor matrona de su siglo y la más fecunda mujer de su ciudad natal, como esposa y como santiaguina, tuvo un doble heroísmo, común empero, en las chilenas, porque dio a su esposo y su patria doce hijos y enseguida murió de parto” (176). Con Lorenza Irarrázabal, se regenera la nación y muere la escritura, su cuerpo dócil, sano y productivo, ya no necesitará ser intervenido por la historia. Chile ha conseguido una madre saludable y conveniente para sus futuros ciudadanos, saludable porque a través de su sangre aristocrática Chile logra la añorada utopía de regeneración y conveniente porque, al morir en el parto, no alcanzará a mezclarse con esas otras madres monstruosas que años más tarde volverán a la Quintrala para poner en entredicho el contrato social republicano que retacea la ciudadanía a las mujeres.

Por último me gustaría señalar que La Quintrala es un texto vacilante entre la historia y la ficción, pero el autor prefiere evitar la ambigüedad y para ello decide crear un apéndice al final del texto donde acumula todos los documentos históricos que dan fe de la existencia de la familia Lisperguer y de la veracidad de su narración. 
De esta manera, Vicuña Mackenna ubica su libro en el campo de la historiografía y, a pesar de reconocerle cierta cualidad mítica, literaria y sociológica, prefiere poner de relieve, en todo momento, el valor documental e histórico del mismo. Vicuña Mackenna recoge de las voces populares la historia de la Quintrala, pero a la hora de legitimar su trabajo elige una disciplina más segura para su escritura. Pareciera que la narración de una verdad supuestamente objetiva y ejemplar, fundamental a la hora de lograr una reconciliación con el pasado, justifica desde el siglo XIX en Chile la intervención de la memoria popular.

Bibliografía

Bello, Joaquín Edwards. La Quintrala, Portales y algo más. Santiago: Editorial Universitaria, 1969.

Collier, Simón y William Sater. A History of Chile, 1808-2002. 2 ed. Cambridge: Cambridge UP, 2004.

Foucault, Michel. Genealogía del racismo. La Plata: Editorial Altamira, 1996. Los anormales. Buenos Aires: FCE, 2000.

Graham, Richard, ed. The Idea of Race in Latin America. Austin: U of Texas P, 1990.

Llanos, Bernardita. "Tradición e historia en la narrativa femenina en Chile: Petit y Valdivieso frente a la Quintrala”. Revista Iberoamericana LX/168-169 (juliodiciembre 1994): 1025-1037.

Leyton Robinson, César. "Historia de la ortopedia urbana 1870-1930". Caber Humanitis 35 (invierno, 2005)

Rama, Ángel. La ciudad letrada. Santiago: Tajamar Editores, 2004.

Ramos, Julio. Desencuentros de la modernidad en América Latina. Literatura y política en el siglo XIX. México: FCE, 1989.

Rénique, José Luis. "Benjamín Vicuña Mackenna: exilio, historia y nación”. Cyberayllu (18 de octubre de 2005). http://www.andes.missouri.edu/andes/ especiales/JLR_Vicuna2 (consulta: 5 de junio de 2007).

Vicuña Mackenna, Benjamín. Los Lisperguer y La Quintrala. Doña Catalina de los Ríos. Santiago de Chile: Sudamericana, 2001.

Páginas de mi diario durante tres años de viaje. Obras Completas v. Santiago: Universidad de Chile, 1936. 